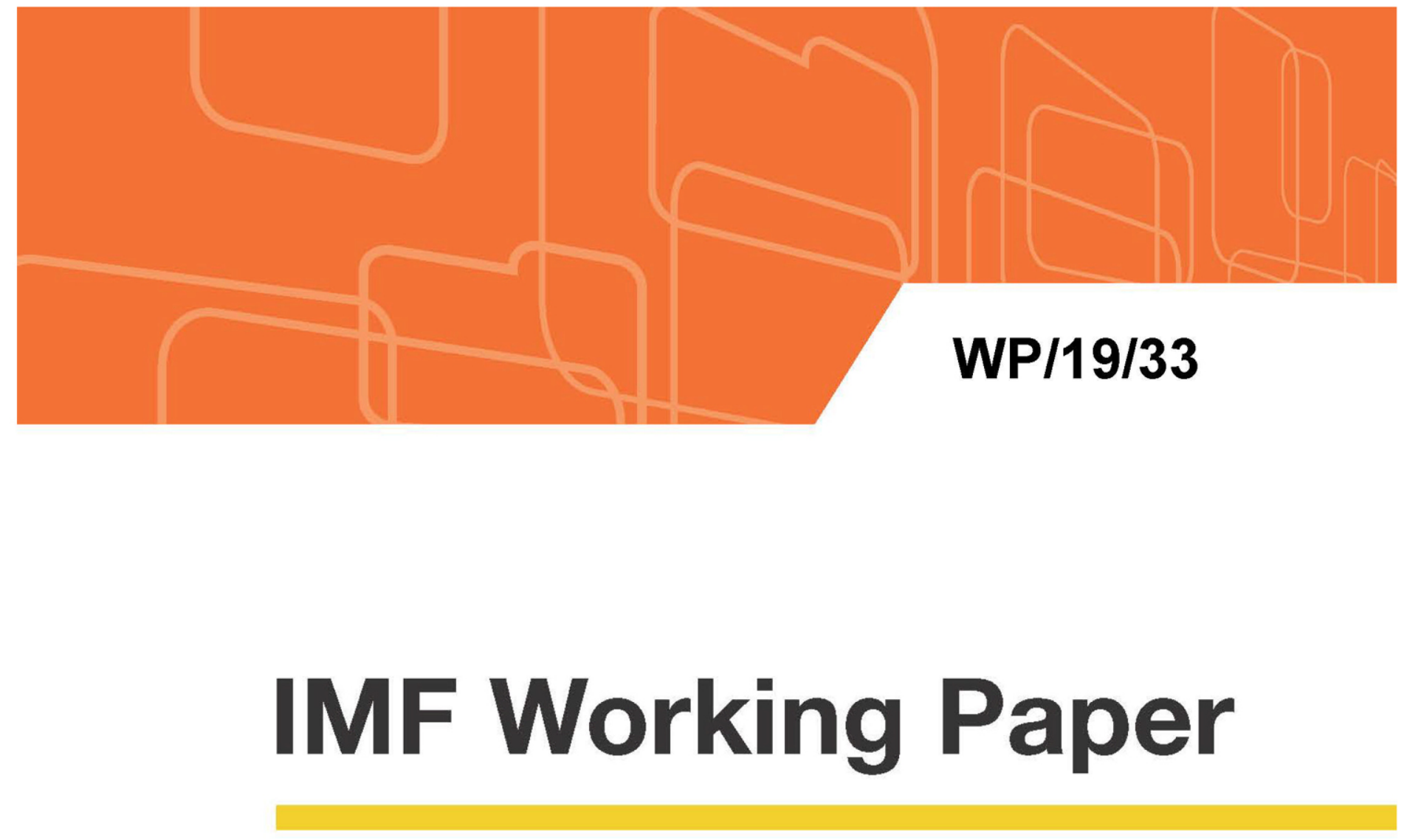

\title{
Mr. Taylor and the Central Bank: Two Inference Exercises
}

by Francesco Luna

IMF Working Papers describe research in progress by the author(s) and are published to elicit comments and to encourage debate. The views expressed in IMF Working Papers are those of the author(s) and do not necessarily represent the views of the IMF, its Executive Board, or IMF management. 


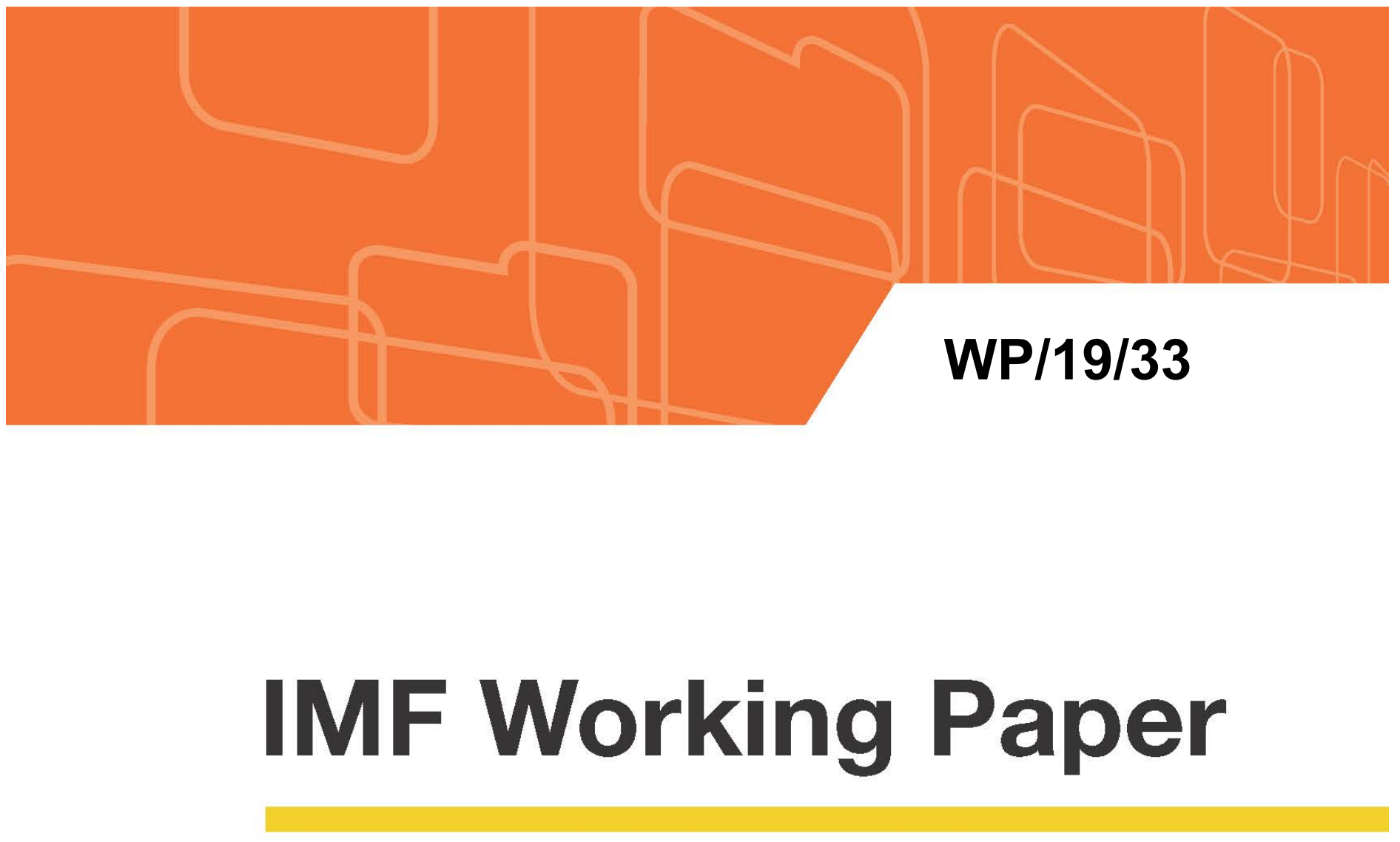

\section{Mr. Taylor and the Central Bank: Two Inference Exercises}

by Francesco Luna

IMF Working Papers describe research in progress by the author(s) and are published to elicit comments and to encourage debate. The views expressed in IMF Working Papers are those of the author(s) and do not necessarily represent the views of the IMF, its Executive Board, or IMF management.

$$
\text { I N T E R N A T | O N A L M O N E T A R Y F U N D }
$$




\title{
IMF Working Paper
}

Institute for Capacity Development

\section{Mr. Taylor and the Central Bank: Two Inference Exercises \\ Prepared by Francesco Luna}

Authorized for distribution by Valerie Cerra

February 2019

\section{IMF Working Papers describe research in progress by the author(s) and are published to elicit comments and to encourage debate. The views expressed in IMF Working Papers are those of the author(s) and do not necessarily represent the views of the IMF, its Executive Board, or IMF management.}

\begin{abstract}
Many observers argue that the world has changed after the latest financial crisis. If that is the case, monetary policy and the process informing it will have to be reconsidered and "learned" anew by all stakeholders. Perhaps, a new Taylor rule will emerge. A "Taylor rule" is predicated upon two successful inference exercises: one by the researcher who is interested in identifying the Central Bank's behavior and one by the Central Bank, which tries to infer how the economy works and interacts with its monetary policy interventions. Because of certain granularities imposed by institutional arrangements and the need for transparent communication in policy making, this paper proposes an analytical framework based on computability theory to model these inference exercises and to assess their general possibility of success. So, is it possible to infer/learn the central bank's policy rule? The answer is a qualified positive and depends on the "complexity" of the economy and on the quality of information. As for policy implications, the results show that transparency and understandable "reaction functions" will go a long way in fostering learnability.
\end{abstract}

JEL Classification Numbers: C00, C69, E58

Keywords: Taylor Rule, learning, computability, computable economics, rational expectations Author's E-Mail Address: fluna@imf.org 


\section{TABLE OF CONTENTS}

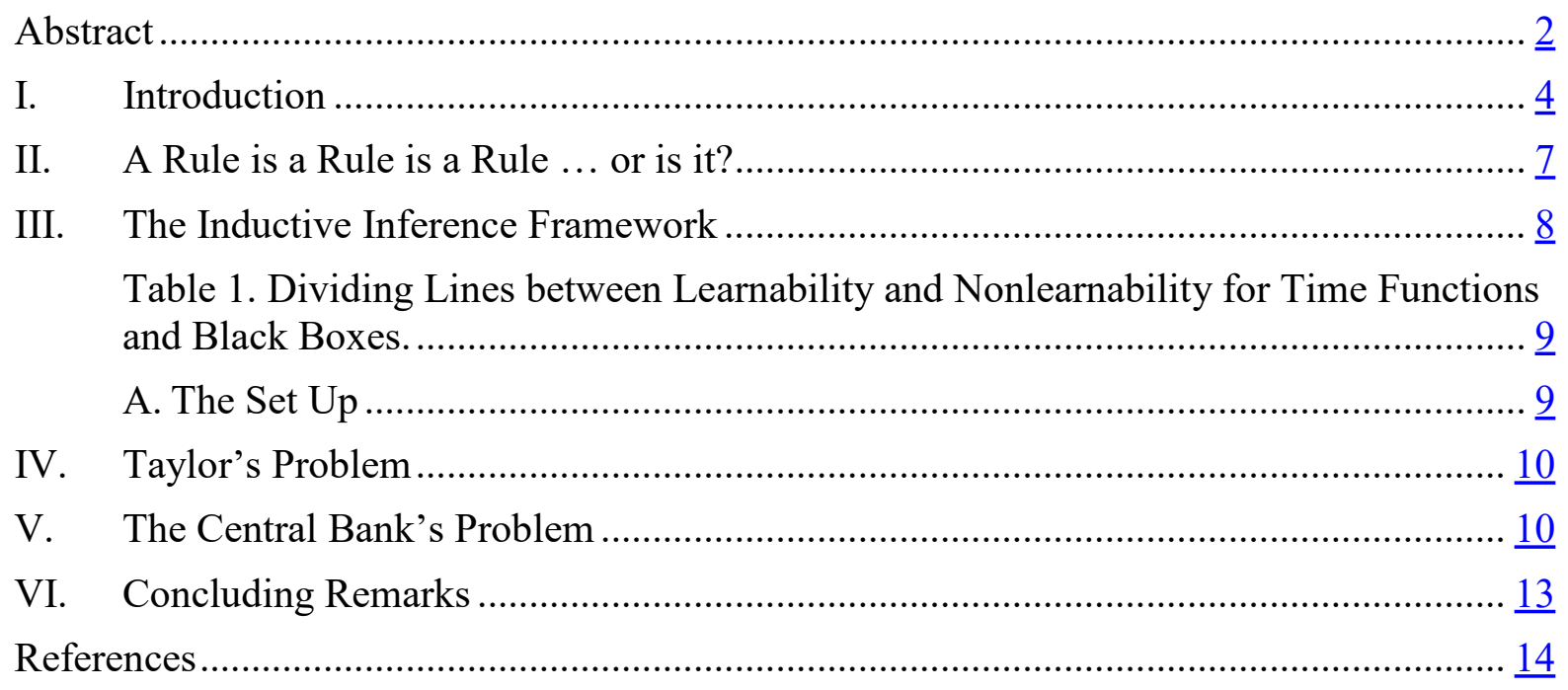




\section{Mr. TAYlor AND THE CENTRAL BANK: Two InFERENCE EXERCISES}

"In sum, many of the most interesting issues in contemporary monetary theory require an analytical framework that involves learning by private agents and possibly the central bank as well."

Ben S. Bernanke (NBER, July 2007)

"[...] a policy rule need not be a mechanical formula,[...]. A policy rule can be implemented and operated more informally by policymakers who recognize the general instrument responses that underly the policy rule, but who also recognize that operating the rule requires judgment and cannot be done by computer".

John B. Taylor (1993, p. 198)

"[...] no central bank (that I am aware of) usues a Taylor rule as the main guide to its instrument-rate setting or has committed itself to a similar instrument rule..."

Lars E. O. Svensson (2003, p. 14)

\section{INTRODUCTION ${ }^{1}$}

If the world has changed after the latest financial crisis, monetary policy may have to be reformulated. Following the observation that price stability does not guarantee financial stability, the profession has debated whether monetary policy should be expanded to encompass that goal as well (Svensson 2011). Whether "traditional" inflation targeting is maintained or the more recent "forecast targeting" regime (Woodford 2007, Svensson 2011b) is adopted, the essential role of a "policy rate" is not doubted, hence some form of the Taylor rule may still be relevant. However, all stake holders will need to learn and understand how this new rule works and through which (new) mechanisms. The same exercise will be (even more) necessary in case the rule is not "simple," but rather the result of some structural welfare maximizing problem.

As stressed in Blinder et ali (2016), the "practice" of monetary policy has changed after the crisis and the question is whether these changes in central bank mandates, monetary policy instruments, central bank communications, and place of central banks within the government

\footnotetext{
${ }^{1}$ This work is dedicated to my professor, mentor, and friend Kumaraswamy, Vela, Velupillai. He introduced me to the fascinating world of computability and with rigor and unwavering intellectual honesty showed how computable economics could provide a new foundation for economic theory.
} 
are to be temporary or permanent. Has quantitative easing (and the institutional framework around it) changed fundamentally and permanently the "stable" relation between inflation, GDP gap, and interest rates? And even accepting the robustness of such a link, what is the relevant concept of "GDP gap"? Indeed, the recent discussion on the volatility of calculated potential output - initially raised by Cerra and Saxena (2017) and more recently resurfaced in Fatas (2018) and Krugman (2018) — points at the need for a continuous re-computation of the relevant parameters if not for a new functional form.

As the literature slowly explores the neighborhood of Rational Expectations Equilibria (REE), Bernanke (2007) stresses that learning — or inductive inference — is at the center of the debate in contemporary monetary theory ${ }^{2}$. Starting from the premise that to endow private agents with rational expectations appears too extreme, is it possible for the private sector to learn Rational Expectations ${ }^{3}$ And, more specific to monetary policy, is Taylor rule (or principle) consistent with a converging learning dynamics by the private sector? The question is pertinent as central bank's "forecast-based rules," for example, could lead to divergent learning dynamics on the part of private agents trying to "learn" REE (see Preston 2005). ${ }^{4}$ In the end, it looks like monetary policy in general, and the new one emerging after the crisis in particular, should also be assessed according to a "learnability criterion," as suggested by Bullard (2006).

There are two inference problems related to Taylor rule. First and obvious is the original one faced by Taylor himself: identify, from the observation of relevant data, the function (rule) employed by the Central Bank to map output gap and inflation rate into a policy rate. We can assume that at least this exercise does not have an impact on the way the system behaves. Using an expression from anthropology, Taylor is a participant observer whose actions are not affecting the observed phenomenon.

The monetary authorities tackle the twin problem: they try to converge - through an inductive process of observation plus trial and error - to a function linking their policymaking process (which is sensitive also, but not exclusively, to inflation and unemployment expectations) plus policy instruments (the policy interest rate in particular) to the variables of interest: growth and inflation.

\footnotetext{
${ }^{2}$ In passing, it may be worth noting that the insistence on "consistent beliefs" is essential to macro theory and monetary policy after the advent of the Rational Expectation Revolution. See, for example, Lejonhufvud (1983). Furthermore, the learnability concept proposed in this paper is "in the limit." In other words, as the learning converge (if it does) to the correct underlying function, the economy remains "out of equilibrium", and perhaps it changes structurally over time. Would it still be relevant to talk about "equilibrium" in such a context?

${ }^{3}$ Such a question, has been asked already many times in the past, for example, by Bray (1982), Evans (1985), Marcet and Sargent (1989a, b), and Spear (1989, in a general setting quite similar to the one proposed here).

${ }^{4}$ Building on Evans and Honkapohja's (2001) concept of E-stability, Honkapohja and Mitra (2005) show that even heterogeneous expectations between the central bank and private agents are consistent with the Taylor principle if the learning rules employed are asymptotically identical.
} 
This paper proposes to embed both the modeling of these inference exercises and the assessment of their "learnability" in a framework founded upon classic recursion theory. There are at least two elements that inform this choice.

(i) Because of institutional restrictions, in many important cases, the policy rate is quite "granular": the minimum change is limited to a quarter of a percent;

(ii) The need for transparency, advocated in the old as well as most recent literature on monetary policy in general, and inflation targeting in particular, translates into rules that need to be codified using some finite alphabet so as to be published/transmitted.

Both these elements suggest that a procedural approach is the most appropriate. If these factors are appreciated to their full extent, then the most general and rigorous way to represent a rule is by using a Turing Machine. ${ }^{5}$

There are multiple advantages in following this approach. First, it encompasses arguably all learning mechanisms or strategies employed in the applied literature, including, for example, the one based on the "Cognitive Consistency Principle", proposed in Evans and Honkapohja (2008), specifically in the context of monetary economics. According to this principle, "economic agents should be as smart as (good) economists,", hence induction (or, equivalently, learning) is modeled through econometric techniques ${ }^{7}$ available to the professional economist with which the economic agent is endowed. Second, a positive result granted by this "learnability criterion" would guarantee that both the policy rule and the learning mechanism proposed can be implemented, simulated, and studied on a digital computer without any loss of generality. Still these methodological "constraints" would not trivialize the exercise: as shown for example by Tchaidze and Carare (2005), even employing the most advanced tools does not guarantee a unique solution of the inference problem.

\footnotetext{
${ }^{5}$ I am here referring to the Church-Turing thesis, which states that any algorithm can be effectively reproduced by a Turing Machine. The thesis, of course, is not a theorem, so there is the possibility that, indeed, there may be a way to encapsulate the idea of a computation that transcends the possibilities of a Turing Machine. Although many attempts have been made since the formulation of the thesis eight decades ago, no such a formulation has been found and various alternative proposals (like the lambda-calculus or register machines) have been shown to be equivalent to the Turing Machine formulation. Hence, this framework is employed very widely in the hard as well as social sciences to identify some absolute boundaries to what can be calculated independently of time and resource constraints.
}

6 Evans and Honkapoja (2008) p. 40.

${ }^{7}$ It is curious to note that the "Principle of Cognitive Consistency" is derived from psychology and used, for example to explain decision-making under stressful conditions...the question is who is under stress: the economic agent or the economist modeling the behavior? 


\section{A Rule is a Rule is a Rule ... OR is it?}

"[...] a policy rule need not be a mechanical formula,[...]. A policy rule can be implemented and operated more informally by policymakers who recognize the general instrument responses that underly the policy rule, but who also recognize that operating the rule requires judgment and cannot be done by computer".

John B. Taylor (1993, p. 198)

Taylor's quote about "rules" is based on a rather narrow and quite widespread conception of what a rule is and of the idea it transmits in the context of monetary economics. As a matter of fact, earlier in the same paper, Taylor mentions Friedman's proposed constant rate of money creation and clearly wants to distance "his" rule from such a simplistic mechanism. On the other hand, it is surprising to read that a computer, according to Taylor, would not be able to implement his envisioned monetary policy rule. Of course, Taylor in this case does not refer to the famous "Taylor rule" as generally known, but to a rule "operated more informally by policymakers...who also recognize that operating the rule requires judgment $[\ldots] .{ }^{8 \text { " It }}$ is interesting to ask whether the impossibility would derive from the large number of contingencies that the policymakers would face. However, if that is what Taylor had in mind, I would be tempted to retort that computer programs that play chess have been famous if not widely popular for more than 20 years ${ }^{9}$, and they certainly can deal with "astronomically" large sets of options. So there could be more to Taylor's statement.

Interestingly enough, the effort of freeing the idea of "rule" from a crude and limited mechanical procedure was still called for ten years after Taylor's 1993 influential contribution. In fact, Svensson (2003) feels necessary to refer to Taylor's paper to reinforce the message and to stress further the need for flexibility and "judgment" encapsulated in the modern conceptualization of monetary policy: "[g]ood monetary policy should not be modeled with ad hoc reaction functions that are not structural, but instead as optimizing policy, with the help of optimal targeting rules ${ }^{10}$." If this "simply" translates into "a more complex reduced-form reaction function in which the instrument rate is a function of all the

\footnotetext{
${ }^{8}$ Taylor (1993) p. 198.

${ }^{9}$ After Shannon's (1950) writing about the problem, a rather famous match between man and computer took place in 1978 between David Levy and Chess 4.7, developed at Northwestern University, and well before Kasparov's duel with IBM Deep Blue.

${ }^{10}$ Svensson (2003) p. 15.
} 
inputs in the forecasting process ${ }^{11}$ ", the only result, as stated, is to increase the complexity of the rule or the reaction function without affecting its inherent nature of algorithm, procedure $^{12}$.

However, Svensson insists that: “...it is better to model monetary policy as optimizing in the same way we model the private sector" and that "...central banks are at least goal-directed, rational, and optimizing as the average household or firm ${ }^{13}$." This, indeed, may introduce a novel element that could be problematic. If, for example, we were to follow the lead and describe the central bank choices as based on a rational preference ordering the way economists in general model consumers' behavior, the choice process itself would, in principle, be ineffective. The result, contained originally in Rustem and Velupillai (1990) and painstakingly worked out in Lilly (1993) was later streamlined in Velupillai (2000) in the ampler context of economic rationality. The scope of this note is however limited so I will overlook this problem, which, however, I believe is related more to the way economists tend to "think" of economic behavior rather than to the way in which policy makers "design" economic measures. I will get back to it in the concluding remarks to assess the possible implications for the more general induction exercise. For the rest of my study, I will maintain that the best way to characterize a rule is through a procedure as flexibly implemented as a Turing Machine can do. At the same time, it is interesting to note, the learning approach I follow is quite similar to the one presented by Spear (1989) who suggested a computability framework to address the question whether economic agents could learn how to form rational expectations. Such a framework would indeed have to accommodate optimizing (and, if the induction process is successful, eventually "perfectly rational") actors, be they consumers, entrepreneurs, or the central bank, hence utterly in line with Svensson's recommendation.

\section{III.THE INDUCTIVE INFERENCE FRAMEWORK}

I refer to the approach proposed, for example, in Gold $(1965,1967)$ on inductive inference in general and language identification in particular. In its most general form, an identification situation comprises three elements:

1. A class of objects;

2. A method of information presentation;

3. A naming relation.

\footnotetext{
${ }^{11}$ Ibid p. 14.

12 Note that this would be true even in the extreme case of "discretionary" behavior of the monetary authority. Indeed, according to McCallum (1999), for example, discretion would translate into a "period-by-period reoptimization on the part of the monetary authority..." (p. 1486). Of course, this would have some implication for the learnability results, but not on the procedural nature of the behavior.

${ }^{13}$ Ibid pp. 14-15.
} 
I will focus only on the learnability results of the following "objects": (i) time functions and (ii) black boxes. A time function takes positive integers (time) into positive integers.

A black box receives an input and returns an output determined by all the inputs that have been applied to the black box up to that moment. More precisely: we will consider a black box as a function $o_{t}=b\left(i_{1}, \ldots . ., i_{t}\right)$ where $i$ stands for input and $o$ is the output. Both $i$ 's and $o$ 's are taken as integers. Of course, a time function is a special case of a black box where the output depends only on $t$ and not on previous inputs.

The method of information presentation is going to be a text $t^{14}$. The naming relation for this exercise is chosen to be a generator ${ }^{15}$, and the name it will guess at each point in time will be a Turing machine that defines a function from positive integers to positive integers. The "learnability" concept will be "identification in the limit", i.e. the time function $T F$ or black box $B B$ will be said to be identified in the limit if, after some finite time, the guesses are all the same and are indeed a name for $T F$ or $B B$. The learnability results can be summarized as follows:

TABLE 1. DIVIDING LINES BETWEEN LEARNABILITY AND NONLEARNABILITY FOR TIME FUNCTIONS AND BLACK BOXES.

\begin{tabular}{lc}
\hline \multicolumn{2}{c}{ Type of object } \\
Time functions
\end{tabular}

Time functions can be identified in the limit only if they are at most primitive recursive, while black boxes can be identified if they are generated by finite automata (ultimately, only periodic functions).

\section{A. The Set UP}

For the time function, at each point in time $t$, a learner is presented with one instance (an integer ${ }^{16}$ for simplicity) belonging to the range of the function and will guess the name (or

\footnotetext{
${ }^{14}$ Another option would be the informant, which gives both positive and negative pieces of information. In other words, at each time it specifies whether the integer presented does or does not belong to the range of the function to be identified.

${ }^{15}$ Again there is another possible naming relation: a tester, which is a decision procedure. For each integer, it will output a 1 whether the number belongs to the range of the function to be identified and a 0 otherwise. Not surprisingly, this implies that the functions that can be learned by using a tester naming relation have to be recursive.

${ }^{16}$ Of course, a rational number will also work.
} 
one of the equivalent names) of the function that generated the sequence observed so far. The learner will be successful in her attempt if, after a finite number of instances, she converges (that is, her guess doesn't change any longer) on the name of the function which indeed generated the sequence.

In the case of a black box identification, at each point in time the learner will (i) input a value in the black box, (ii) observe the output; (iii) form her guess. In the case of a black box, the learnability concept must be somewhat weakened, since there is the possibility that the input may trigger a "structural change" that constrains the function to a subset of its initial range. So weak learnability implies that only the future behavior of the black box is to be inferred.

\section{IV.TAYLOR's PROBLEM}

As mentioned, the fundamental hypothesis in this case, is that "Taylor", the learner, does not affect the object in his attempt to identify it. Hence, the framework is quite "simple" and immediately linked to the results above: Taylor is dealing with a time function. At each point in time $t$, he is presented with one instance (an integer ${ }^{17}$ for simplicity) belonging to the range of the function and will guess the name (one of the equivalent names) of the function which generated the sequence observed so far. Taylor will be successful in his attempt if, after a finite number of instances, he converges (that is, his guess doesn't change any longer) on the name of the function which indeed generated the sequence. The formulation would be:

$$
i=\varphi_{T}(\omega)
$$

Where $i$ is the nominal interest rate and $\omega$ is an integer ${ }^{18}$ obtained univocally combining $u$, a measure of the output gap (or unemployment gap) and $\pi$ the inflation rate. The problem is to identify the "name" $T$ of the function (Turing Machine) underlying the Taylor rule "used" by the Central Bank.

According to the table above, as long as the function is primitive recursive, such an exercise is in principle feasible. Needless to say, this result reveals nothing on the complexity of the task, that is, no hint is given on how long it may take or what resources it may require. Rather, it fixes some impassable border: classes of more complex functions cannot be identified.

\section{The Central Bank's Problem}

"[A] reaction function in which the real funds rate changes by roughly equal amounts in response to deviations of inflation from a target of 2 percent and to deviations of actual from

\footnotetext{
${ }^{17}$ A rational number will work too. Also, multiple inputs can be reduced to a single integer through bijective functions similar to the one in the next footnote.

${ }^{18}$ For example, $\omega=\langle i, \pi\rangle=1 / 2\left(i^{2}+2 i \pi+\pi^{2}+3 i+\pi\right)$, as I learned in Rustem and Velupillai (1990).
} 
potential output describes reasonably well what this committee has done since 1986."

Janet Yellen at the January 1995 FOMC

"Philosophy Master(PM): Because, sir, there is no other way to express oneself than with prose or verse. Monsieur Jourdain $(M J)$ : There is nothing but prose or verse? PM: No, sir, everything that is not prose is verse, and everything that is not verse is prose.

$M J:$ And when one speaks, what is that then?

P M: Prose.

MJ: What! When I say, "Nicole, bring me my slippers, and give me my nightcap," that's prose?

P M: Yes, Sir.

M J: By my faith! For more than forty years I have been speaking prose without knowing anything about it, and I am much obliged to you for having taught me that."

Molière (Le Bourgeois Gentilhomme, Act Two, Scene Four)

Whether or not Ms. Yellen was indeed obliged to Taylor for having identified the prose the committee had been speaking for many years, the assumption about the abstract nature of the observer (the absolute disconnect between the learning process and the object to be learned) does not hold any more when we consider the inference problem from the Central Bank's perspective. This is because in its learning exercise, the Central Bank affects the very behavior of the economy it needs to infer to design its policy. This complication has essential implications for the learnability of the function. Assume that indeed the Central Bank wants to use a Taylor rule. Then, it wants to make sure that it will "choose" a rule that is "consistent" with the economy.

Let me elaborate: the central bank has determined a target for inflation - and possibly for the level of economic activity - that is considered optimal for stability and sustainable growth prospects. In order to achieve those objectives, the central bank manipulates, according to some "rule" $P$, its main instrument: the policy interest rate. The economy will "react," taking as input not only the data $i$, but also the rule $P$ (which could be interpreted as including the expectation mechanism applied by the central bank). Based on this input, it (the economy) will consequently output inflation and unemployment functions ${ }^{19}$.

\footnotetext{
${ }^{19}$ In reality, a line of research advanced for example by Orphanides (2001) well documents yet another level of "complexity". The information set employed by the CB in its policy making, may be incomplete or imprecise and subject to later revisions: think of GDP data available only quarterly or even data on the output gap where "potential" output is revised significantly (especially after the financial crisis, as mentioned above). Certainly,
} 
Using the typical recursive function notation, we can summarize the above "prose" in the following way. For the Central Bank:

$$
\omega=\varphi_{P}(i)
$$

$\omega$ is the integer representation of $u$ and $\pi . \varphi_{P}$ is the policy rule adopted by the CB that is supposed to map $i$ into $u$ and $\pi$. However, the economy will map

$$
\omega=\varphi_{g[P]}(i)
$$

This implies that the central bank is looking for a fixed-point rule:

$$
P=g[P]
$$

Note that $P$ is the inverse of the $T$ rule that Taylor is trying to infer.

One way to model the Central Bank's learning process is through a two-step procedure:

1) the Central Bank, holding the rule $P$ fixed, observes $\omega$ and tries to infer $\varphi_{\mathrm{g}[\mathrm{P}]}$

2 ) by changing its policy rule $P$ the central bank tries to infer $g[\cdot]$

In case of full information:

Proposition 1: If the economy mapping $\varphi_{\mathrm{g}[\mathrm{P}]}$ from integers to integers is primitive recursive it can be learned in the limit.

Proof. By the learnability results of time functions.

Proposition 2: If the function $g[\cdot]$ is periodic (generated by a finite automata ${ }^{20}$ ), it can be learned in the limit.

Proof. By the learnability results of black boxes.

Proposition 2 deviates from Spear's (1989) results in a similar context. According to Spear also $g[\cdot]$ could be inferred in case it is primitive recursive. However, as argued above, I think that this would require quite a heroic assumption. In practice, it implies that the impact of the monetary policy framework on the economy is nil and the insistence on modeling the central bank's behavior in structural form would be quite irrelevant.

these considerations should be relevant even for the Taylor-like researcher, making the other induction exercise more complex. We will abstract from these considerations proposing the results in case of "full information" and add some observations in the concluding section.

${ }^{20}$ I refer the interested reader to the classic book by Hopcroft and Ullman (1979). To introduce here the concept of finite automata and compare it with that of a Turing Machine is beyond the purpose of this study. It suffices here to stress that a finite automaton can generate "simpler" functions. 


\section{CONCLUDing REMARKS}

In a full information context, the Taylor-like researcher should be able to identify up to the class of primitive recursive Taylor rules ${ }^{21}$. As mentioned above, the function to be inferred by the researcher would be the inverse of the monetary policy rule implemented by the authorities. This implies that, were the policy rule itself primitive recursive, the complexity of its inverse could in principle transcend this level making the Taylor-like quest unfeasible.

As for the monetary authorities, their task would be more daunting and they could infer the economy's behavior - hence successfully implement a Taylor-like monetary policy ruleonly in case the economy is well represented by a finite-automata black box.

In case information is incomplete, Velupillai (2000) synthetically shows how the positive results of the general inductive inference problem do not hold anymore and I refer the interested reader to that book. However, I would like to point at a specific source of noise that has been stressed quite recently in the literature on monetary policy, prompted by the ever more popular inflation targeting "revolution." It relates to the issue of transparency and effective communication by central banks ${ }^{22}$. The recurring preoccupation with contradictory signals contained in the official communication of the central bank, may be interpreted as introducing yet another source of noise in the sequence of information (on the "text") from which the learner is to infer the underlying function. On such "noisy texts", as shown by Osherson, Stobb, and Weinstein (1986), the learnability results fail in case the contradictory elements, even though from a finite set, may be repeated an infinite number of times. Of course, this has dramatic implications from a policy perspective calling for not only transparent, but also consistent communication. On the other hand, invoking another result from Osherson et al. we can state that the learnability results will hold even though a finite portion of the information set is never presented. This seems quite important as it suggests that it would be possible to infer what the central bank would do in extreme situations even though those cases have not presented themselves during the "successful" learning process. Finally, it is important to stress that, even though we may agree to adopt or consider only effective policy measures ${ }^{23}$, we may still doubt that the economy itself be a computable object. In case the economy is uncomputable, the results obtained could still give an answer to the question "is Taylor rule learnable through computable inductive inference procedures?" The answer, in general, would be in the negative, but, of course, it would not imply that specific problems could not be solved.

\footnotetext{
${ }^{21}$ In the broader sense than the simple "[..] reaction function in which the real funds rate changes by roughly equal amounts in response to deviations of inflation from a target of 2 percent and to deviations of actual from potential output".

${ }^{22}$ See for example Dennis and Williams (2007) and Freedman and Laxton (2009). Bulir, Smidkova, Kotlan, and Navratil (2008), and Bulir and Cihak (2008) propose a way to quantify how "clear" or without contradiction a central bank's communication is.

${ }^{23}$ Policies that can be codified and successfully executed by a Turing Machine.
} 


\section{REFERENCES}

Blinder, Alan s., Ehrmann, M., de Haan, J., Jansen, D-J. (2016), "Necessity as the Mother of Invention: Monetary Policy After the Crisis,” NBER WP Series 22735, (Cambridge, MA)

Bray, Margaret (1982), "Learning, Estimation, and the Stability of Rational Expectations," Journal of Economic Theory, April 1982, 26(2), pp. 318-39.

Bulir, A.; Smidkova, K.; Kotlan, V.;Navratil, D. (2008), "Inflation Targeting and Communication: Should the Public Read Inflation Reports or Tea Leaves?”, IMF working paper (Washington: International Monetary Fund)

Bulir, A.; Cihak, M.; Smidkova, K., (2008) “Writing clearly: ECB’s Monetary Policy Communication,” IMF working paper (Washington: International Monetary Fund).

Cerra, V.; Saxena, S.C., (2017) "Booms, Crises, and Recoveries: A New Paradigm of the Business Cycle and its Policy Implications,” IMF working paper No. 17/250 (Washington: International Monetary Fund). https://www.imf.org/en/Publications/WP/Issues/2017/11/16/Booms-Crises-and-RecoveriesA-New-Paradigm-of-the-Business-Cycle-and-its-Policy-Implications-45368

Dennis, R.; and Williams J.C. (2007), "Monetary Policy Transparency, and Credibility: Conference Summary," FRBSF Economic Letter, 2007-12 (San Francisco: Federal Reserve Bank of San Francisco). http://www.frbsf.org/publications/economics/letter/2007/el200712.pdf.

Evans, George W. (1985), "Expectation Stability and the Multiple Equilibria Problem in Linear Rational Expectations Models," Quarterly Journal of Economics, November 1985, 100(4), pp. 1217-33.

Evans, George; and Honkapoja, Seppo (2001), Learning and Expectations in Macroeconomics. Princeton NJ: Princeton University Press.

Evans, George; and Honkapoja, Seppo (2008), "Expectations, Learning and Monetary Policy: An Overview of Recent Research", Centre for Dynamic Macroeconomic Analysis Working Papers Series, CDMA 08/02.

Fatás, Antonio (2018), "Fiscal Policy, potential output and the shifting goalposts", CEPR Discussion Paper 13149.

Freedman, C; and Laxton, Douglas (2009), “Inflation Targeting Pillars: Transparency and Accountability," IMF working paper (Washington: International Monetary Fund). 
Gold, Mark E. (1965), “Limiting Recursion,” Journal of Symbolic Logic, 30, pp. 28-48.

Gold, Mark E. (1967), "Language Identification in the Limit," Information and Control, 10, pp. 447-474.

Honkapohja, Seppo; and Mitra, Kaushik (2005), "Performance of Inflation Targeting Based on Constant Interest Rate Projections," Journal of Economic Dynamics and Control, November 2005, 45(1), pp. 141-73.

Hopcroft, John; and Jeffrey Ullman (1979), Introduction to Automata Theory, Lanuages, and Computation, Reading, Massachusetts: Addison-Wesley Publishing Company.

Krugman, Paul (2018), “The Economic Future Isn't What It Used to Be (Wonkish) Long run economic prospects fell sharply after the Great Recession," The New York Times, September 30, 2018

Leijonhufvud, Axel (1983), "Keynesianism, Monetarism, and Rational Expectations: Some reflections and Conjectures", in Frydman and Phelps, eds, Individual Forecasting and Aggregate Outcomes:'Rational Expectations' Examined, Cambridge University Press, New York.

Lilly, Gregory (1993), "Recursiveness and Preference Orderings," Journal of Economic Dynamics and Control, September-November 1993, v. 17, iss. 5-6, pp. 865-76.

Marcet, Albert; and Sargent Thomas J. (1989a), "Convergence of Least-Squares Learning Mechanisms in Self-referential Linear Stochastic Models," Journal of Economic Theory, August 1989, 48(2), pp.337-68.

Marcet, Albert; and Sargent Thomas J. (1989b), "Convergence of Least-Squares Learning in Environments with Hidden State Variables and Private Information," Journal of Political Economy, December 1989 97(6), pp.1396-22.

McCallum, Bennett (1999), "Issues in the design of Monetary Policy Rules," in Handbook of Macroeconomics, Volume 1, edited by JB Taylor and M. Woodford, Elsevier Science B.V., pp.1483-1530.

Orphanides, Athanasios (2001), "Monetary Policy Rules based on Real-Time Data," The American Economic Review, September 2001, v. 91, iss. 4, pp. 964-85

Osherson, D.N.; Stob, M.; Weinstein, S. (1986), Systems That Learn, MIT University Press. 
Rustem, Berc; Velupillai, Kumaraswamy (1990), "Rationality, Computability, and Complexity," Journal of Economic Dynamics and Control, May 1990, v. 14, iss. 2, pp. 41932.

Spear, Stephen (1989); "Learning Rational Expectations under Computability Constraints," Econometrica, July 1989, v. 57, iss. 4, pp. 889-910.

Svensson, Lars E.O. (2003), "Monetary Policy and Learning," Economic Review of the Federal Reserve Bank of Atlanta, Third Quarter, pp. 11-16.

Svensson, Lars E.O. (2011), "Monetary policy after the crisis", Federal Reserve Bank of San Francisco, Proceedings, issue Nov, pp. 35-49.

Svensson, Lars E.O. (2011b), "Practical Monetary Policy: Examples from Sweden and the United States.” Brookings Papers on Economic Activity. Fall, pp. 289-332.

Taylor, John B. (1993), “Discretion Versus Policy Rules in Practice,” Carnegie-Rochester Conference Series on Public Policy 39 pp195-214.

Tchaidze, Robert; and Alina Carare (2005), "the Use and Abuse of Taylor Rules: How Precisely Can We Estimate Them?”, IMF Working Paper No. 05/148 (Washington: International Monetary Fund).

Velupillai, Kumaraswamy (2000), Computable Economics, Oxford University Press.

Woodford, Michael. (2007), "The Case for Forecast Targeting as a Monetary Policy Strategy." Journal of Economic Perspectives 21, pp. 3-24. 